Dr Yam Bahadur Roka

MS, M.Ch., IFAANS

Address for correspondence:

Senior Consultant and Head

Department of Neurosurgery

Neuro Cardio and MultiSpeciality hospital,

Biratnagar, Nepal

dryamroka@yahoo.com

Date submitted : 2/4/2019

Date accepted : 3/5/2019

\section{Review in The Management of Post-Craniotomy Pain}

Pain can lead to increase in the sympathetic stimulation and thereby cause hypertension and rebleed in the operative site. The ideal management of pain in these circumstances is a topic of debate worldwide. The standard algorithm for pain management is usually with nonsteroidal anti-inflammatory drugs (NSAIDS) with or without opioids. Good pain management helps to reduce not only the pain but also shortens hospital stay and cost and leads to early recovery but overenthusiastic use of drugs can lead to sedation, mydriasis, respiratory depression which could increase the intracranial pressure or obtundation of deteriorating neurological signs. There is thus no Gold Standard drugs or algorithm to manage post craniotomy pain and this review aims to discuss the common availability of medicine and review the various options available for successful management of post craniotomy pain (PCP). Each neurosurgical centre must have a protocol and guidelines regarding PCP management which will be easier for the juniors and nurses to follow. Multimodality treatment can achieve best results and further controlled trials with the different medications alone or in combination, studies in cannabinoid derivatives in future can help to formulate and ideal PCP management algorithm.

Key words: Craniotomy, Opioid, NSAIDs, Nerve block, Morphine, Gabapentin, PostCraniotomy headache

\footnotetext{
$\mathrm{A}$ ny surgical intervention leads to pain and thus the latter management is also a key factor in Craniotomy is the most common neurosurgical procedure worldwide for almost all types of neurosurgical diseases and thus is the commonest cause of headache and pain in these cases. Postoperative pain causes a great deal of alarm, concern, anxiety, doubt in treatment, feeling of failure and even depression in patients. This type of pain is found to be commoner in females and younger
}

patients. ${ }^{23}$ The International Headache Society has defined post-craniotomy headache as that developing within a week after surgery and lasting till 3 months in Acute and beyond 3 months in chronic type.

Pain can lead to increase in the sympathetic stimulation and thereby cause hypertension and rebleed in the operative site. The ideal management of pain in these circumstances is a topic of debate worldwide. The exact incidence of pain postoperatively varies because it also depends on the type of surgery, the counselling, 
Roka et al
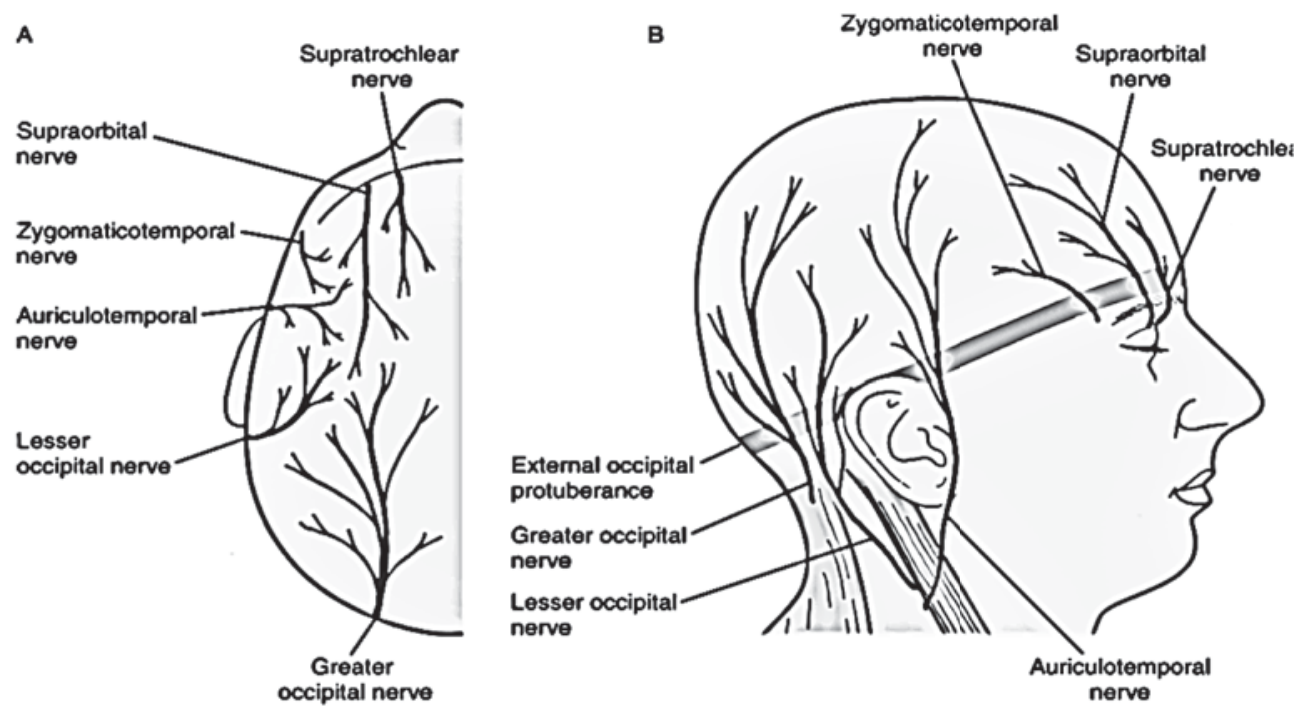

Figure 1. The sensory supply of the scalp and the potential sites for nerve block. ${ }^{15}$

the psychology of the patient and the perioperative analgesia used. In one of the earliest studies pain was found to be moderate to severe in around $60 \%{ }^{6,8,28}$ The standard algorithm for pain management is usually with nonsteroidal anti-inflammatory drugs (NSAIDS) with or without opioids. ${ }^{36}$ good pain management helps to reduce not only the pain but also shortens hospital stay and cost and leads to early recovery but overenthusiastic use of drugs can lead to sedation, mydriasis, respiratory depression which could increase the intracranial pressure or obtundation of deteriorating neurological signs. There is thus no Gold Standard drugs or algorithm to manage post craniotomy pain and this review aims to discuss the common availability of medicine and review the various options available for successful management of post craniotomy pain (PCP).

\section{The post-craniotomy pain pathogenesis: ${ }^{7,28}$}

PCP is typically a dull aching pain, mingling with headache, either localized to the incision site or a headache which is pulsating, tightening, band like which is aggravated by coughing, sneezing, exercise or head or neck movement. It may be associated with nausea, vertigo, tinnitus and photophobia.The pain is somatic and due to the dissection of the muscles and tissues and is more severe in surgery of the posterior fossa and subtemporal region where more extensive dissection of the thick muscles is needed. Excessive traction, cautery,dural tension, aseptic meningitis, bone dust, muscle or vascular manipulation in the scalp can increase the pain. Localized cerebrospinal fluid (CSF) collection also leads to features of meningism and headache. Females and the younger population are more prone for PCP while males and elderly are comparatively better tolerant to pain. ${ }^{2}$ Females had $40 \%$ more incidence of headaches and majority of them rated that as severe. ${ }^{11}$ PCP is maximum 48 hours after surgery and one third may still have pain beyond this time.The International Headache Society has defined postcraniotomy headache as that developing within a week after surgery, regaining of consciousness after surgery and discontinuation of medication(s) impairing ability to sense or report headache following the craniotomy, and lasting till 3 months in Acute and beyond 3 months in Chronic type provided other causes of headache are excluded. ${ }^{37}$ Chronic PCP is usually associated with surgery of acoustic neuroma and last till a year. ${ }^{29}$

\section{Options in the Prevention of PCP}

Localscalpinfiltration, non-pharmacologicaltreatment, pharmacological treatment and surgical methods are the options available for PCP control.

\section{Scalp infiltration:}

The scalp has an extensive network of sensory nerves and their manipulation during surgery can lead to further central sensitization leading to enhanced pain perception in future. Infiltration of some drugs like Bupivacine $0.5 \%$ or Ropivacaine with or without Lidocaine has been found to significantly reduce PCP without any side effects and last till 48 hours. ${ }^{11,13,14,26,36}$ This can be supplemented with nerve blocks like maxillary nerve block, for further pain control.Figure 1 shows the nerves supplying the scalp where blocks can be made.

\section{Surgical Techniques to reduce $\mathbf{P C P}^{18,27,35,33}$}

Numerous steps taken during surgery can lead to significant reduction of PCP. Clean and neat dissection, without excessive use of cautery, retraction, muscle manipulation and removal of bone dust can also reduce 
Post craniotomy pain

\begin{tabular}{|c|c|c|}
\hline \multirow[b]{2}{*}{ Drug } & \multicolumn{2}{|l|}{ Starting doses and intervals } \\
\hline & $<50 \mathrm{~kg}\left(\mathrm{mg} \cdot \mathrm{kg}^{-1}\right)$ & $>50 \mathrm{~kg}$ and adult ( $\mathrm{mg}$ flat dose) \\
\hline Ketorolac & $0.5 \mathrm{mg} \cdot \mathrm{kg}^{-1} \mathrm{IM} / \mathrm{IV} \mathrm{Q} 6 \mathrm{H}$, up to maximum of $72 \mathrm{~h}^{\mathrm{a}}$ & $\begin{array}{l}15-30 \mathrm{mg} \mathrm{Q} 6 \mathrm{H} \text {, not to exceed } 120 \mathrm{mg}^{- \text {day }^{-1} \text {. up to }} \\
\text { a maximum of } 72 \mathrm{~h}\end{array}$ \\
\hline Ibuprofen & 5-10 $\mathrm{mg} \cdot \mathrm{kg}^{-1} \mathrm{PO}$; not to exceed $40 \mathrm{mg} \cdot \mathrm{kg}^{-1} \cdot$ day $^{-1 a}$ & $200-800 \mathrm{mg}$ PO Q $6 \mathrm{H}$ \\
\hline \multirow{14}{*}{ Acetaminophen } & Oral & Oral \\
\hline & Neonates & $325 \mathrm{mg}$ PO Q $4 \mathrm{H}-\mathrm{O} 6 \mathrm{H}$ \\
\hline & Dose: $10-15 \mathrm{mg} \cdot \mathrm{kg}^{-1} \mathrm{PO}$ q6-8h & OR \\
\hline & Max: $60 \mathrm{mg} \cdot \mathrm{kg}^{-1} \cdot \mathrm{day}^{-1}$ & $500 \mathrm{mg}$ PO Q $6-8 \mathrm{H}$ \\
\hline & Infants/children & OR \\
\hline & Dose: $10-15 \mathrm{mg} \cdot \mathrm{kg}^{-1} \mathrm{PO} \mathrm{q} 4-6 \mathrm{~h}$ & $625 \mathrm{mg} \mathrm{PO} \mathrm{O} 8 \mathrm{H}$ \\
\hline & Max: $75 \mathrm{mg} \cdot \mathrm{kg}^{-1} \cdot \mathrm{day}^{-1}$ up to $1 \mathrm{~g}$ per $4 \mathrm{~h}$ and $4 \mathrm{~g} \cdot \mathrm{day}^{-1}$ & Not to exceed $4 \mathrm{~g} \cdot \mathrm{day}^{-1}$ \\
\hline & $>12$ years & \\
\hline & Dose: $325-650 \mathrm{mg}$ PO q4-6h & \\
\hline & IV & IV \\
\hline & $12.5 \mathrm{mg} \cdot \mathrm{kg}^{-1} \mathrm{IV} \mathrm{Q} 4 \mathrm{H}$ & $650 \mathrm{mg} \mathrm{IV} \mathrm{Q} 4 \mathrm{H}$ \\
\hline & OR & OR \\
\hline & $15 \mathrm{mg} \cdot \mathrm{kg}^{-1} \mathrm{IVO} 6 \mathrm{H}$ & $1000 \mathrm{mg}$ IV O $6 \mathrm{H}$ \\
\hline & Not to exceed $750 \mathrm{mg}$ per dose and $80 \mathrm{mg} \cdot \mathrm{kg}^{-1} \cdot \mathrm{day}^{-1}$ & Not to exceed $4 \mathrm{~g} \cdot \mathrm{day}^{-1}$ \\
\hline Clonidine & $\begin{array}{l}\text { Oral and transdermal } \\
1 \mu \mathrm{gg} \cdot \mathrm{kg}^{-1} \cdot \mathrm{dose}^{-1} \mathrm{Q}_{4} \mathrm{HPO}\end{array}$ & $\begin{array}{l}\text { Oral and transdermal } \\
1 \mu \mathrm{g} \cdot \mathrm{kg}^{-1} \cdot \mathrm{dose}^{-1} \mathrm{O} 4 \mathrm{HPO}\end{array}$ \\
\hline \multirow[t]{4}{*}{ Diazepam } & Oral & Oral \\
\hline & $0.25-0.3 \mathrm{mg} \cdot \mathrm{kg}^{-1} \mathrm{Q} 6-8 \mathrm{~h}$ & $2-10 \mathrm{mg} \cdot \mathrm{kg}^{-1} \cdot \mathrm{day}^{-1} \mathrm{Q} 6-8 \mathrm{~h}$ \\
\hline & IV & IV \\
\hline & $0.05-0.1 \mathrm{mg} \cdot \mathrm{kg}^{-1} \mathrm{Q} 4-6 \mathrm{H}$ & $\begin{array}{l}2-10 \mathrm{mg} \text { IV/IM O } 3-4 \mathrm{H} \\
\text { No more than } 30 \mathrm{mg} \text { per } 8 \mathrm{~h}\end{array}$ \\
\hline \multirow[t]{4}{*}{ Gabapentin } & $3-12$ years & $300 \mathrm{mg}$ PO OHS, then gradually increase as tolerated \\
\hline & $10-15 \mathrm{mg} \cdot \mathrm{kg}^{-1} \cdot$ day $^{-1}$ divided $\mathrm{Q} 8 \mathrm{H}$ & to $300 \mathrm{mg} \mathrm{Q} 8 \mathrm{H}$ \\
\hline & $>12$ years & \\
\hline & $300 \mathrm{mg} \mathrm{PO} \mathrm{Q} 8 \mathrm{H}$, may increase up to $600 \mathrm{mg} \mathrm{PO} \mathrm{Q} 8 \mathrm{H}$ & \\
\hline \multirow[t]{4}{*}{ Amitriptyline } & Load & Load \\
\hline & $0.1 \mathrm{mg} \cdot \mathrm{kg}^{-1} \mathrm{PO} \mathrm{OHS}$; increase as tolerated over $2-3$ weeks & $75 \mathrm{mg} \cdot \mathrm{day}^{-1} \mathrm{PO}$ \\
\hline & Maintenance & Maintenance \\
\hline & $0.5-2 \mathrm{mg} \cdot \mathrm{kg}^{-1} \mathrm{PO} \mathrm{OHS}$ & $150-300 \mathrm{mg} \cdot$ day $^{-1}$ orally in single or divided doses \\
\hline
\end{tabular}

a Safety of nonsteroidal antiinflammatory drugs (NSAIDs) such as ketorolac or ibuprofen in children less than 3-6 months of age is not well established.

Figure 2. Showing the dosage of non opioidal analgesics that are commonly used for PCP relief..$^{34}$

PCP. Bone flap replacement cause significantly less PCP than craniectomy at discharge and one-year followup. Watertightdural closure with reduced CSF leak is a possible cause for the reduced PCP. Studies have found insertion of bone cement, adipose tissue graft and use of augmentation duraplasty showed reduction of PCP.

\section{Pharmacological treatment of PCP}

An ideal neurosurgical analgesic medication should be able to give good relief of pain, have anti-inflammatory properties, should not affect the central nervous system functions, hinder consciousness or neurological assessment, shouldn't cause cardio-respiratory depression, is not addictive and with no side effects like vomiting, nausea, epilepsy or local bleeding.Sadly, there is no drug that fits this category and hence neurosurgeons worldwide have to rely on different medications in isolation of in combination for PCP management. In a study from UK it was found that only $65 \%$ of neurosurgical centres had analgesic protocols and over the decades Morphine was the first line analgesic used followed by paracetamol
(84\%) and NSAIDs (52\%). Codeine use reduced from $90 \%$ to $70 \%$ over the same time period. ${ }^{19,30}$

\section{Non-Opiod Analgesics/ NSAIDs (Figure 2)}

Paracetamol/ Acetaminophen: this has been used alone or in a combination to reduce PCP. The exact mechanism of action is unclear although it may act by Beta-Endorphin receptor modulation, prostaglandin $\mathrm{H} 2$ receptor synthetase or a central nervous painkiller action. Patient with liver disease are cautioned. Acetaminophen also acts by inhibiting COX-3 inhibition and descending serotonergic pathways. It has minimal anti-inflammatory and antiplatelet effect and at doses of 10-15 mg per Kg has few serious side effects. It can be given intravenous, orally or in pediatric patients per rectally(at a higher dosage of 25-40 mg per Kg). ${ }^{1,4}$ It has been used with Sufentanil combination with better PCP control.

NSAIDs: these are another group of very commonly used analgesics (ibuprofen, diclofenac, Naprosyn, ketorolac) which reduce PCP, reduce inflammation and has no opioid like side effects. These act as cyclooxygenase 
Roka et al

\begin{tabular}{|c|c|c|c|}
\hline Drug & Parenteral/oral ratio & \multicolumn{2}{|l|}{ Starting doses and intervals } \\
\hline \multicolumn{4}{|l|}{ (a) Oral agents } \\
\hline \multicolumn{4}{|l|}{ Morphine } \\
\hline Immediate release & $1: 3$ & $0.3 \mathrm{mg} \cdot \mathrm{kg}^{-1} \mathrm{Q} 3-4 \mathrm{~h}$ & $15-20 \mathrm{mg} Q 3-4 \mathrm{~h}$ \\
\hline Sustained release & $1: 5$ & Flat dose only!! & $30-45 \mathrm{mg} 08-12 \mathrm{~h}$ \\
\hline Hydromorphone & $1: 2-1: 4$ & $0.03-0.08 \mathrm{mg} \cdot \mathrm{kg}^{-1} \mathrm{O} 3-4 \mathrm{~h}$ & $1-2 \mathrm{mg} \mathrm{Q} \mathrm{3-4h}$ \\
\hline Methadone & $1: 1-1: 2$ & $0.2 \mathrm{mg} \cdot \mathrm{kg}^{-1} \mathrm{O} 48 \mathrm{~h}$ & $10 \mathrm{mg} \mathrm{Q} 48 \mathrm{~h}$ \\
\hline \multirow[t]{2}{*}{ Codeine } & \multicolumn{2}{|r|}{$\mathrm{NR}^{\mathrm{a}}$} & $30-60 \mathrm{mg} Q 3-4 \mathrm{~h}$ \\
\hline & & Starting doses and intervals & \\
\hline Drug & Equianalgesic IV dose (mg) & $<50 \mathrm{~kg}\left(\mathrm{mg} \cdot \mathrm{kg}^{-1}\right)$ & $>50 \mathrm{~kg}$ and adult ( $\mathrm{mg}$ flat dose) \\
\hline \multicolumn{4}{|l|}{ (b) Parenteral agents } \\
\hline & & Infusion & Infusion \\
\hline & & $0.025 \mathrm{mg} \cdot \mathrm{kg}^{-1} \cdot \mathrm{h}^{-1}$ & $1-2 \mathrm{mg} \cdot \mathrm{h}^{-1}$ \\
\hline \multirow[t]{4}{*}{ Hydromorphone } & $1.5-2$ & Bolus & Bolus \\
\hline & & $0.015 \mathrm{mg} \cdot \mathrm{kg}^{-1} \mathrm{Q} 1-2 \mathrm{~h}$ & $1 \mathrm{mg} Q 1-2 \mathrm{~h}$ \\
\hline & & Infusion & Infusion \\
\hline & & $2-4 \mu \mathrm{g} \cdot \mathrm{kg}^{-1} \cdot \mathrm{h}^{-1}$ & $0.2-0.3 \mathrm{mg} \cdot \mathrm{h}^{-1}$ \\
\hline Methadone & 10 & $0.1 \mathrm{mg} \cdot \mathrm{kg}^{-1} \mathrm{Q} 4-8 \mathrm{~h}$ & $5-10 \mathrm{mg} \mathrm{Q} 4-8 \mathrm{~h}$ \\
\hline Meperidine & $75-100$ & $\mathrm{NR}^{\mathrm{b}}$ & NR \\
\hline
\end{tabular}

${ }^{a}$ Due to the FDA black box warning against use of this drug in postop pediatric T\&A patients, and evidence of pharmacogenetic metabolic variation, the use of this drug is not recommended for pediatric neurosurgical patients (49-51).

beperidine is metabolized to normeperidine which can cause seizures.

Figure 3. Showing the common opioidal drugs and their dosage. ${ }^{34}$

2 inhibitor (COX) and can cause platelet dysfunction and increase bleeding (COX-1 isomer) and analgesia by (COX-2 isomer). Selective COX-2 inhibitor does not have anti-platelet effects and therefore do not cause bleeding. The effectiveness of COX-2 inhibitors (parecoxib, rofecoxib) in relieving pain has been well proven in other surgical specialities. ${ }^{3,16}$ In a study of the use of parecoxib $40 \mathrm{mg}$ in craniotomy patients it was found to decrease pain score and morphine use but with no significant analgesia effect. ${ }^{17}$ The limitations of the COX-2 inhibitors are the potential to cause myocardial infarction which was shown in the Vioxx Gastrointestinal Outcomes Research (VIGOR) trial leading to withdrawal of rofecoxib. COX-2 inhibitors also inhibit important renal prostanoids leading to hyperkalemia, salt retention, hypertension with potential increase of heart failure. ${ }^{32}$

Dexmedetomidine: is a selective alpha2-adrenergic agonist acting at central and peripheral level as a nonopiod analgesic. There are several studies that has shown the beneficial effect of this drug in PCP with good pain control, reduced use of postoperative morphine although time to extubation was not different. Bradycardia can be a significant side effect of using this drug and lead to a cause of alarm in postoperative period. ${ }^{25}$

Gabapentinoids: these are analgesics that act via the Alpha2-delta subunit of N-type voltage gated Calcium channels by reduction in excitatory neurotransmission. They also have opioid sparing effects and few studies have shown the beneficial effects of single dose of preoperative gabapentin. Gabapentin was first used as an anti-epileptic for partial seizures. Pregabalin which is a gabapentin derivative has also analgesic and anti-epileptic properties. Further trials are needed using this drug and its results in PCP management. The most common side effects of this drug are peripheral edema, giddiness, drowsiness and ataxia. ${ }^{5,22}$

Dexamethasone: can reduce inflammation and thus help in reducing pain. This has been used to reduce ICP and along with Gabapentinoids or Phenytoin to manage PCP. ${ }^{22}$

NMDA receptor antagonist: Methadone and Ketamine can cause analgesia as an NMDA receptor antagonist and can be used in single or with NSAIDS or opioids perioperatively. It has opioid sparing property and has been used in spine and other non-neurosurgical procedures. Ketamine has the potential for raising ICP and thus studies are limited regarding its use in PCP management. ${ }^{20}$

Other Miscellaneous:Amitriptyline, diazepam, sodium valproate, carbamazepine and clonidine are some other drugs used for pain management.

Opioid Analgesic [Greek “opion-poppy plant juice”] 


\section{Post craniotomy pain}

Tramadol: the classical side effects of opioids like sedation, dizziness, vomiting, dry mouth, nausea, vomiting, miosis can hide the true signs of neurological deterioration and hence the use of opioids was not common in neurosurgery. Tramadol is a weak analgesic acting as the Mu-receptor agonist or serotonin/ norepinephrine reuptake inhibition. It does not affect coagulation or platelet function and hence is theoretically safe in neurosurgery. Tramadol use has shown not only to reduce the hospital stay by 24 hours but also the overall cost of analgesics used by 32 US $\$ .^{38}$ Long term use can lead to physical dependence and even withdrawal syndrome like hallucination, anxiety, panic attack, paresthesia and numbness usually within a day of stopping medication. Its use has been likened to that of heroin in high doses. Its use along with opioid analgesic and acetaminophen can further enhance PCP management.

Narcotic drugs: [Greek "narco- to deaden”] these include, morphine, hydrocodone, remifentanil, codeine, fentanyl, oxycodone and propoxyphene. They act by stimulating, mu (morphine), kappa and sigma subtype opioid receptors in the peripheral and central nervous system. The mu receptor depending on the site and function are further divided into mu1-supraspinal analgesia, mu2- gastrointestinal motility inhibition and respiratory depression and mu3-that act on leukocytes and have anti-inflammatory actions. ${ }^{24}$ The important side effects like respiratory depression is a major deterrents of the use of opioids in neurosurgery and thus used only for short duration based on the individual hospital protocol. They can be used as bolus, intravenous infusions, patientcontrolled devices or as needed basis pro re natawith equal efficacy. It can be converted to oral dosage once patient stabilizes. Intramuscular route is also used but has the disadvantage of slower absorption and delayed action.Fentanyl when compared with morphine is fast acting, lipopholic and has a shorter duration of action and can also be used as a transdermalpatch or transmucosal/ transnasal route. The transmuscosal/nasal route by passes the first-pass hepatic metabolism and thus is more efficient in PCP management. The skin condition, ethnicity, age, location and temperature can affect the transdermal route absorption and the drug can still be absorbed 24 hours even after the patch is removed. Remifentanil is another potent rapid action drug and is associated with better hemodynamic control during induction and improved level of consciousness and has been studied for awake craniotomy. ${ }^{10}$

Use of capnography and inductance plethysmography helps in the early diagnosis and management of respiratory depression in those using continuous pump infusions. Oxycodone is preferred over codeine as it does not need the cytochrome P450 2D6 isoenzyme to metabolize and hence is safer in those with the latter deficiency.Constipation needs special care as many of the neurosurgical patients are bedridden for a long time. Nausea and itching can also be severe in some cases.The dosage guidelines of the common opioids are given in Figure $3 .^{34}$

Management of chronic PCP: these are a subtype of patients that complain of persistent headache or pain after craniotomy. Other causes like cervical spondylosis, psychiatric illness, fibromyalgia, migraines and tension headaches must be ruled out. NSAIDs are the first line drugs and if they are not helpful then amitriptyline, gabapentinoids, carbamazepine or sodium valproate can be used. Antiepileptics can help to control both postoperative seizures and treat headaches too. Local analgesia, steroid injections, Botox injections, removal of stitch scars are other interventions to relieve pain. If permissible Cannabis derived products have potential to treat chronic PCP. ${ }^{21}$

\section{Conclusion}

PCP is a common problem in as many as $80 \%$ of cases have moderate to severe pain which may not be adequately treated as the brain is assumed to be insensitive to pain. Inadequate PCP management can lead to a multiple of problems like anxiety, hypertension, headache and postoperative bleeding. The proper management would thus involve perioperative nerve block with local incision site infiltration and good postoperative analgesia. The visual analog scale/ pain scale chart isuseful tool to assess the PCP and decide on the type of analgesic to be used. The factors like age, sex, possible psychology, site of operation and metabolic diseases or clinical factors need to be considered. For mild pain, NSAIDs can be used as they are cheap, easily available, quick acting, minimal side effects of sedation or nausea/vomiting and do not alter the consciousness levels. They can be used alone or in combination. For severe pain opioids can be used in either continuous infusion, transdermal or transnasal or transmucosal routes. Patient controlled pain releasing devices are also useful where available. While trying to achieve a painless postoperative stay is important one must not forget the potential side effects of using analgesics which could be immediate or in future. Timely identification and management of complications of analgesics is as important as starting the medications. Topical analgesics, cold compression, transcutaneous electrical stimulation and psychological counselling can benefit in a subset of patients.

Each neurosurgical centre must have a protocol and guidelines regarding PCP management which will be easier for the juniors and nurses to follow. Multimodality 


\section{Roka et al}

treatment can achieve best results and further controlled trials with the differentmedications alone or in combination, studies in cannabinoid derivatives in future can help to formulate and ideal PCP management algorithm.

The ideal plan of action would be Preoperative counselling with local nerve block of infiltration followed by Opioidal analgesics on a continuous, bolus, or as per demand analgesia supplemented with paracetamol and followed up with gabapentinoids or amitryptylline for chronic pain can benefit patients with PCP.

\section{References:}

1. Anderson BJ. Paracetamol (Acetaminophen): mechanisms of action. PediatrAnesth 18: 915-921, 2008

2. Ayrian E, Kaye AD, Varner CL, et al. Effects of anesthetic management on early postoperative recovery, hemodynamics and pain after supratentorial craniotomy. J Clin Med Res 7 (10):731-741, 2015

3. Bekker A, Cooper PR, Frempong-Boadu A, Babu R, Errico T, Lebovits A. Evaluation of preoperative administration of the cyclooxygenase- 2 inhibitor rofecoxib for the treatment of postoperative pain after lumbar disc surgery. Neurosurgery 50 (5):10531057, 2002

4. Birmingham PK, Tobin MJ, Fisher DM et al. Initial and subsequent dosing of rectal acetaminophen in children: a 24-hour pharmacokinetic study of new dose recommendations. Anesthesiology 94: 385 389, 2001

5. Dahl J, Mathiesen O, Møiniche S. 'Protective premedication': an option with gabapentin and related drugs? A review of gabapentin and pregabalin in in the treatment of post-operative pain. Acta AnaesthesiolScand 48 (9):1130-1136, 2004

6. De Benedittis G, Lorenzetti A, Migliore M, Spagnoli D, Tiberio F, Villani RM. Postoperative pain in neurosurgery. J NeurosurgAnesthesiol8:315-6, 1996

7. de Gray LC, Matta BF. Acute and chronic pain following craniotomy: a review. Anaesthesia 60 (7):693-704, 2005

8. Dunbar PJ, Visco E, Lam AM. Craniotomy procedures are associated with less analgesic requirements than other surgical procedures. Anesthesia\&Analgesia 88 (2): 335-340,1999

9. Dunn LK, Naik BI, Nemergut EC, Durieux ME. PostCraniotomy Pain Management: Beyond Opioids. Curr Neurol Neurosci Rep 16 (10):93, 2016

10. Gelb AW, Salevsky F, Chung F, Ringaert K, McTaggart-Cowan RM, Wong T, et al. Remifentanil with morphine transitional analgesia shortens neurological recovery compared to fentanyl for supratentorial craniotomy. Can J Anaesth 50 (9):946-52, 2003

11. Gottschalk A, Berkow LC, Stevens RD, Mirski M, Thompson RE, White ED, Weingart JD, Long DM, Yaster M. Prospective evaluation of pain and analgesic use following major elective intracranial surgery. J Neurosurg 106 (2):210-6, 2007

12. Gottschalk, Allan MD, PhD; Yaster, Myron MD. Pain Management After Craniotomy. Neurosurgery Quarterly 17 (1): 64-73, 2007

13. Gray LCD, Matta BF. Acute and chronic pain following craniotomy: a review. Anaesthesia 60:693-704, 2005

14. Haldar R, Kaushal A, Gupta D, Srivastava S, Singh PK. Pain following craniotomy: reassessment of the available options. BioMed Research International :1-8, 2015

15. https://accessemergencymedicine.mhmedical.com/ content . aspx ?bookid $=683 \&$ sectionid $=45343770$ (accessed April 2019)

16. Hubbard RC, Naumann TM, Traylor L, Dhadda S. Parecoxib sodium has opioid-sparing effects in patients undergoing total knee arthroplasty under spinal anaesthesia. Br J Anaesth 90(2):166-172, 2003

17. Jones SJ, Cormack J, Murphy MA, Scott DA. Parecoxib for analgesia after craniotomy. Br J Anaesth 1 (1):76-79, 2009

18. Koperer H, Deinsberger W, Jodicke A, Boker DK. Postoperative headache after the lateral suboccipital approach: craniotomy versus craniectomy. Minim Invasive Neurosurg (MIN) 42 (4):175-8, 1999

19. Kotak D, Cheserem B, Solth A. A survey of postcraniotomy analgesia in British neurosurgical centres: time for perceptions and prescribing to change? Br $\mathbf{J}$ Neurosurg 23 (5):538-42, 2009

20. Loftus RW, Yeager MP, Clark JA, Brown JR, Abdu WA, Sengupta DK, et al. Intraoperative ketamine reduces perioperative opiate consumption in opiatedependent patients with chronic back pain undergoing back surgery. Anesthesiology 113 (3):639-46, 2010

21. Lutman B, Bloom J, Nussenblatt B, Romo V. A Contemporary Perspective on the Management of Post-Craniotomy Headache and Pain. Curr Pain Headache Rep 22 (10):69, 2018

22. Misra S, Parthasarathi G, Vilanilam GC. The effect of gabapentin premedication on postoperative nausea, vomiting, and pain in patients on preoperative dexamethasone undergoing craniotomy for 


\section{Post craniotomy pain}

intracranial tumors. J NeurosurgAnesthesiol 25 (4):386-391, 2013

23. Notermans S L, Tophoff, MM, Sex differences in pain tolerance and pain perception.Psychiatria, Neurologia, Neurochirurgia 70 (1):23-39,1967

24. Pasternak GW. Molecular biology of opioid analgesia. J Pain Symptom Manage 29 (5 Suppl): S2-S9, 2005

25. Peng K, Jin XH, Liu SL, Ji FH. Effect of intraoperative dexmedetomidine on post-craniotomy pain. Clin Ther 37 (5):1114-21, 2015

26. PinoskyML, FishmanRL, ReevesST, HarveySC, PatelS, PaleschY, Dorman BH. The effect of bupivacaine skull block on the hemodynamic response to craniotomy. Anesth Analg 83 (6):125661, 1996

27. Porter RG Sr, Leonetti JP, Ksiazek J, Anderson D. Association between adipose graft usage and postoperative headache after retrosigmoid craniotomy. Otol Neurotol 30 (5):635-639, 2009

28. Quiney N, Cooper R, Stoneham M, Walters F. Pain after craniotomy. A time for reappraisal? $\mathbf{B r} \mathbf{J}$ Neurosurg 10 (3):295-299, 1996

29. Rimaaja T, Haanpaa M, Blomstedt G, Farkkila M. Headaches after acoustic neuroma surgery. Cephalalgia 27 (10): 1128-35, 2007

30. Roberts GC. Post-craniotomy analgesia: current practices in British neurosurgical centres-a survey of post-craniotomy analgesic practices. Eur J Anaesthesiol 22 (5):328-32, 2005

31. Ryzenman JM, Pensak ML, Tew JM Jr. Headache: a quality of life analysis in a cohort of 1,657 patients undergoing acoustic neuroma surgery; results from the acoustic neuroma association. Laryngoscope 115 (4):703-11, 2005

32. Sanghi S, MacLaughlin EJ, Jewell CW, Chaffer S, Naus PJ, Watson LE, Dostal DE. Cyclooxygenase-2 inhibitors: a painful lesson. Cardiovasc HematolDisord Drug Targets 6 (2):85-100, 2006

33. Schaller B, Baumann A. Headache after removal of vestibular schwannoma via the retrosigmoid approach: a long-term followup-study. Otolaryngol Head Neck Surg 128 (3):387-95,2003

34. Shay JE, Kattail D, Morad A, Yaster M. The postoperative management of pain from intracranial surgery in pediatric neurosurgical patients. PaediatrAnaesth 24 (7):724-33, 2014

35. Teo MK, Eljamel. Role of craniotomy repair in reducing postoperative headaches after a retrosigmoid approach. Neurosurgery 67 (5):1286-91, 2010

36. Vadivelu N, Kai A, Tran D, Kodumudi G, Legler A, Ayrian E. Options for perioperative pain management in neurosurgery. An in-depth review of the current available pharmacologic treatment options for neurosurgical pain. Journal of Pain Research 37: 2016

37. www.ichd-3.org/5-headache-attributed-to-traumaor-injury-to-the-head-andor-neck/5-6-persistentheadache-attributed-to-craniotomy/ (Accessed April 2019)

38. Zhang AZ, Pasternak GW. Ontogeny of opioid pharmacology and receptors: high and low affinity site differences. Eur J Pharmacol 73: 29 -40. 44, 1981 